\title{
Assessing the Power and Effectiveness of a Single and Dual Purposed Refrigerator
}

\author{
Esther Benedicta Kyere ${ }^{1}$, Martin Amoah ${ }^{2}$ \\ ${ }^{1}$ Lecturer, Department of Automotive, Refrigeration and Air Conditioning Engineering, Takoradi Technical University, Western Region \\ (Ghana) \\ ${ }^{2}$ Lecturer, Department of Design and Technology Education, University of Education, Winneba (Ghana)
}

\begin{abstract}
Refrigerator is a device use to keep items at respective temperature, generally at low temperature to preserve items. To reduce the demand for electricity in a household, efforts have been made to make this device more resourceful and efficient, by utilizing the waste heat from the condenser of the refrigerator to heat water and for space heating. To achieve this, modifications are done on the normal refrigerator; but it is not knownif the modification affects the power consumption and the effectiveness of the refrigerator or not. This study investigated the power consumed and the refrigeration effect of the normal and modified refrigerators with load. A major finding was that the maximum temperature achieved in the water tank with 12 liters of water was $52^{\circ} \mathrm{C}$ at 21600 sand the refrigerating temperature of the two units was $7^{\circ} \mathrm{C}$ whilst reducing the total energy consumption from the two systems if used separately. The experiment provedthat the refrigerator was not affected by the modifications. Therefore, the dual purposed refrigerator is technically feasible; thus making it possible to save energy and to safeguard the environment.
\end{abstract}

Keywords: Refrigerator, Energy, cooling effect, modified refrigerator

\section{Introduction}

Refrigeration is a process in which work is done to move heat from one location to another. During refrigeration, heat from the refrigerant is dissipated for the successful completion of a refrigeration cycle. The refrigerator is a device used for food preservation, cooling of water and also used by many industries for preserving many materials, drugs, etc. In normal household refrigerators, the heat from the refrigerant is removed using a condenser where the refrigerant cools and the air surrounding the condenser heats up.

In most cases household refrigerators use air-cooled condensers. The heat from the condenser side is dissipated to the room air. Households need both refrigeration and water heating. Refrigeration is employed for food preservation, while hot water is used for bathing and showering. But it is common for refrigeration and water heating system to be separate and unconnected, each consuming the purchased energy.

A more efficient use of this electrical energy would be to integrate the refrigeration and hot water systems. This would reduce the electrical power consumed by heating water.

Many researchers have come out with designs and reviews on how to recover and utilize the heat from the refrigerator: Kaushik and Singh [1], presented an investigation of the feasibility of HR from the condenser of VCR system through a Canopus heat exchanger(CHE) between the compressor and condenser components. Mirji [2], developed a multipurpose warming apparatus utilizing the waste heat of domestic refrigerator. Mukuna and Kilfoil [3], researched into the technical feasibility of

Combined Refrigerator/Heat Exchanger and Geyser System. O'Brien and Bansal [4], constructed aprototype refrigerationcum-hot water heating system for domestic use. Patil and
Dange [5], recovered waste heat from condenser unit of household refrigerator to improve the performance of the system by using thermo syphon andSlama [6], developed a water-heater coupled with the refrigerator to develop the heat of the condenser.

This research relates to a process to assess the normal refrigerator and the integrated refrigerator (dual purposed) to ascertain if there will be a change in performance or if more power would be consumed if the modification is done on the normal refrigerator; to make use of the waste heat.

\section{Modification and Construction}

The refrigerators and the experimental apparatus for recovering the heat from the condenser were designed, developed and constructed at the University of Education; Kumasi campus , Ghana. Two single door refrigerators of $12 \mathrm{~L}$ capacity and designed to used refrigerant $134 \mathrm{a}$ were used for the study. One was the normal refrigerator and the other modified to make use of the waste heat.

2.1 Components of the Normal and the Dual purposed refrigerators
1) Evaporator
2) Compressor
3) Expansion valve
4) Condenser
5) Water tank (heating section) 


\section{International Journal of Science and Research (IJSR) \\ ISSN (Online): 2319-7064}

Index Copernicus Value (2015): 78.96 | Impact Factor (2015): 6.391

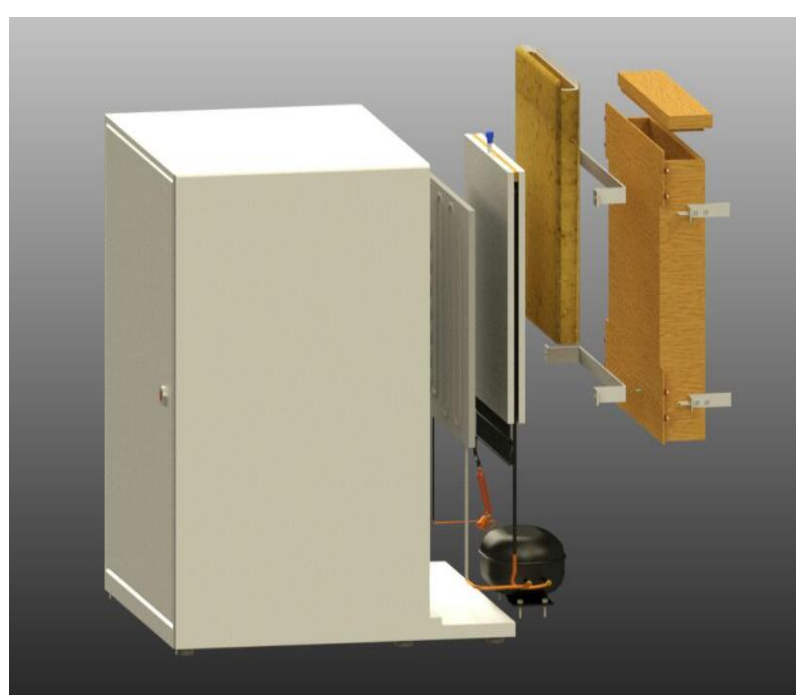

Figure 1 (a): The connection of the four basic components

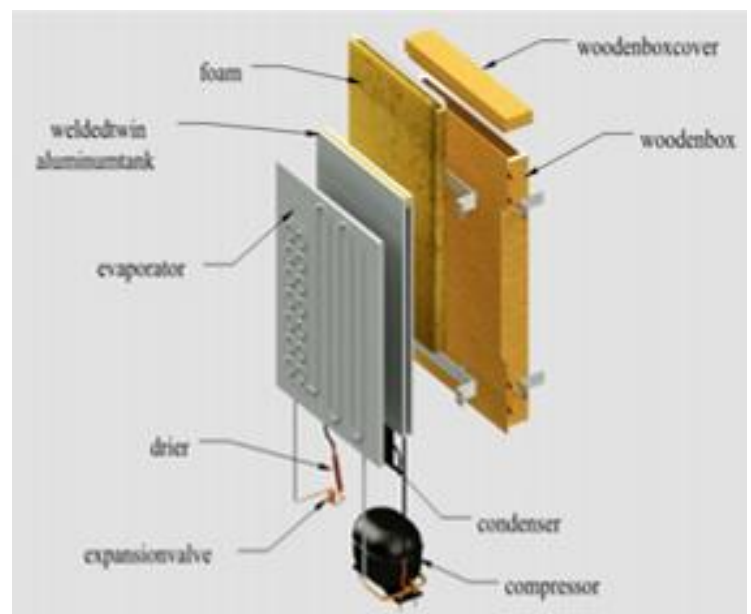

Figure 1 (b): Shows the heating section of the dual purposed refrigerator

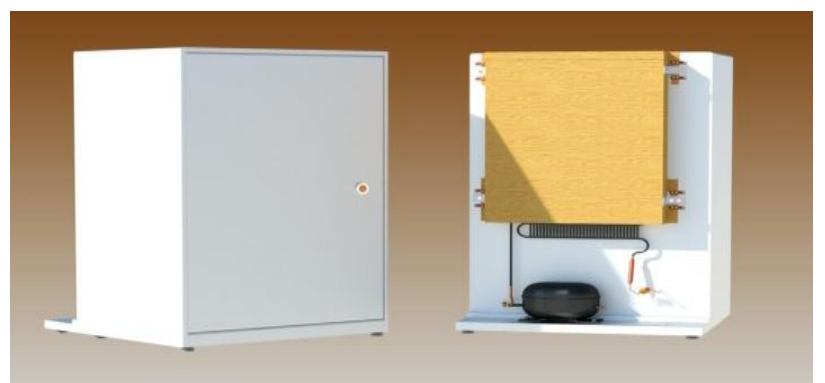

Figure 2: Shows the complete single and dual purposed refrigerator respectively

\subsubsection{Components Arrangement}

For the normal refrigerator, the evaporator was placed inside the refrigerator cabinet and the air cooled condenser placed at the back of the refrigerator. The compressor consists of two charge lines and one discharge line. The evaporator is connected to one of the charge lines of the compressor. The discharge line of the compressor is connected to the condenser placed at the back of the refrigerator and then connected to the expansion valve and to the inlet of evaporator which is placed inside the cabinet. All the connections were made using Copper tubes.

The dual purposed refrigerator (i.e. the normal refrigerator modified) has the same arrangement as the normal refrigerator. The modification was at the back of the refrigerator; that is an introduction of water tank. Water tankisanexternal chamberwhichisattached to the refrigerator; It is made of two aluminum tanks welded together at the upper part to make one unit. The condenser is placed in between the two tanks and together insulated with foam and wood to minimize heat loses. Two rows of the condenser coils were left beneath for radiation. The whole assembly was firmly held in place by the help of hinges and screws.

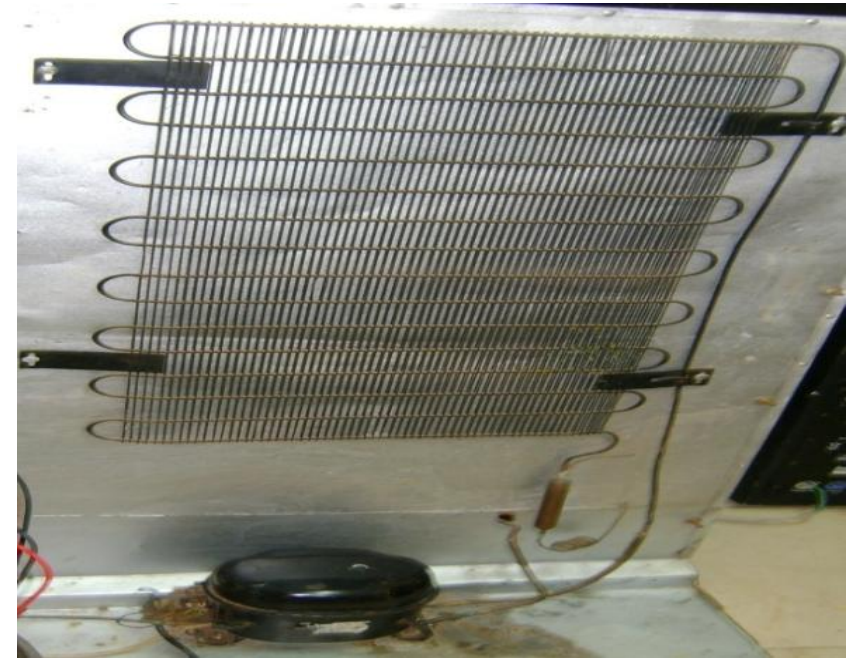

Figure 3: Shows the back of the normal refrigerator

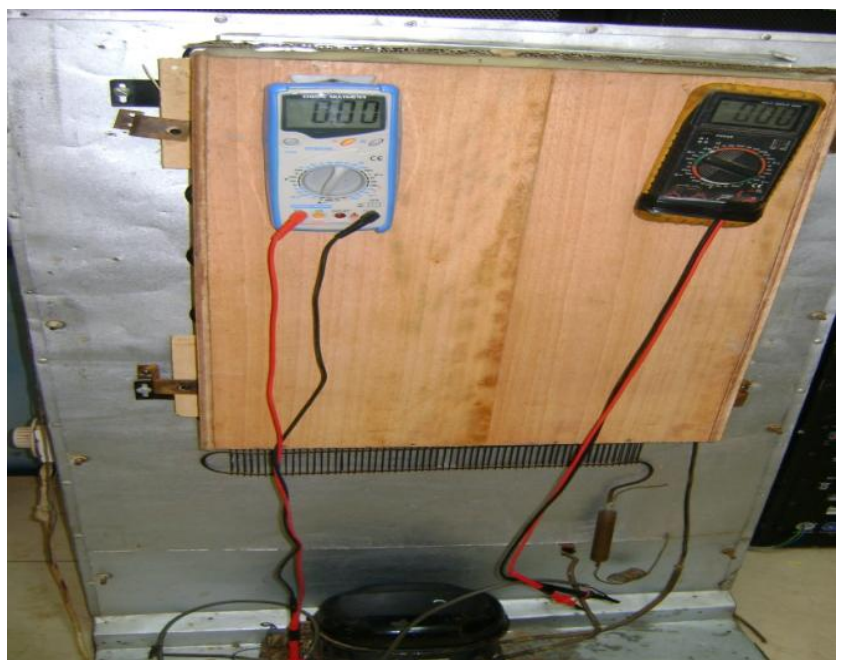

Figure 4: Shows the back of the dual purposed refrigerator

\subsection{Principle of operation of the normal and dual purposed refrigerator}

\section{For the normal refrigerator,}

Evaporator: Low pressure and low temperature liquidrefrigerant from the expansion valve enters the evaporator; where it absorb heat from the substance kept inside the refrigerated space. Thereby making the substance cool and the refrigerant converted into low pressure and high temperature vapour refrigerant. Thus during evaporation, the process is constantpressureprocess.

Compressor: The low pressure vapour refrigerant from the evaporatorentersthecompressor. The compressor compressed this low vapour refrigerant into high pressure

\section{Volume 6 Issue 7, July 2017 www.ijsr.net}




\section{International Journal of Science and Research (IJSR) \\ ISSN (Online): 2319-7064}

Index Copernicus Value (2015): 78.96 | Impact Factor (2015): 6.391

vapour refrigerant, with the temperature further increased due to compression of refrigerant. At the end of compression, the refrigerant is high pressure high temperature vapour refrigerant.

Condenser: The high pressure, high temperature (superheated or saturated) vapour from the compressor enters the condenser. Heat is removed from it and as a result it is condensed back into a liquid phase, low temperature liquid refrigerant.

Expansion valve: The low temperature liquid refrigerant enter into expansion valve where it expand a diabatically, here the expansion valve used is the capillary tube since it reduces the cost of refrigerator. By suddenly reducing pressure a conditional change will occur and the liquid begins to boil and evaporate in the evaporator.

For the Dual purposed refrigerator, the principle of operation is the same as in the normal refrigerator, the only difference is the heating section attached.

Heating section/condenser: - The high pressure high temperature vapour refrigerant from the compressor enters the condenser coils from the top. It flowsintothe coils which are located between the twin water tanks welded together. While flowing through the coils, it makes the water tank warm and the water which is placed in the tank absorbs this heat and become warm.

Open coil section: After going through the coils located between the twin water tank, the refrigerant now flows through the open coil section (part of the condenser coils located beneath the water tank.) where it come in contact with the air for further cooling and the high temperature vapour refrigerant is converted into low temperature liquid refrigerant.

\subsection{WhatMakes the Dual purposed refrigerator Different \\ During operation of normal refrigerators, the high pressure vapour refrigerant from the compressor is changed into liquid refrigerant as it flows through the coils of the condenser.}

The condensing coils are in contact with the air; when the refrigerant flow through these coils by the convection process it becomes cool and converts it into liquid refrigerant. During this process, heat is lost to the surrounding.

In the dual purposed refrigerator, utilization of this heat energy is made; by introducing the double welded aluminum tank. The condenser coils are fixed in between the two aluminum tanks welded together and wrap with foam and wood to insulate it; so that the heat remains entrap in the tank to heat the water inside.

\subsection{Data Collection}

The major tools used for data collection were the two refrigerators to help in the assessment, mercury in glass thermometers for taking the temperatures of the compressor, the cooling effect and the heating effect; multi meters for measuring the current and voltages.

The temperatures of the cooling and heating effect and the compressor of the refrigerators were measured with mercury in glass thermometers. The thermometers were fitted at the outlet of the compressor, in the water inside the refrigerator compartment of the refrigerator and the combined unit; and the water in the water tank at the back of the combined unit. The current and the voltage of both units were taken with time using a timer. The data (values) were recorded in thirty minutes for six hours.

The refrigerator's performance with no load (no water tank) attached and with load attached was assessed using the data recorded.

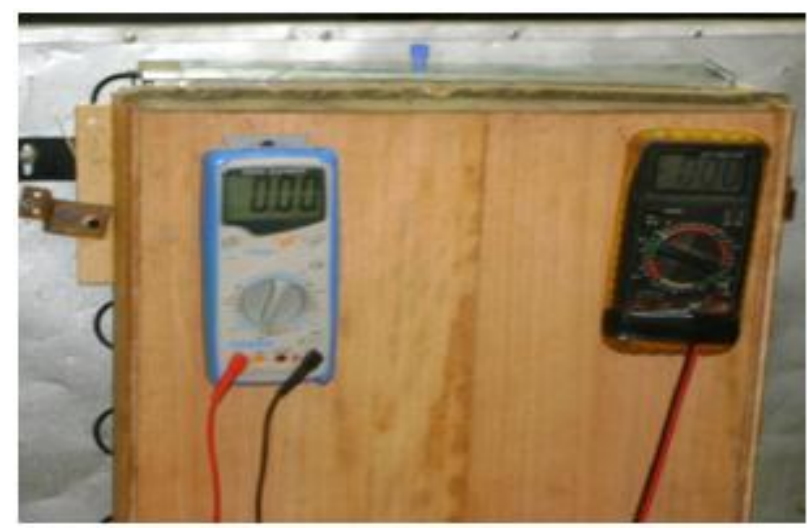

Figure 5 (a): set up for taking the temperatures of the water in the tank.

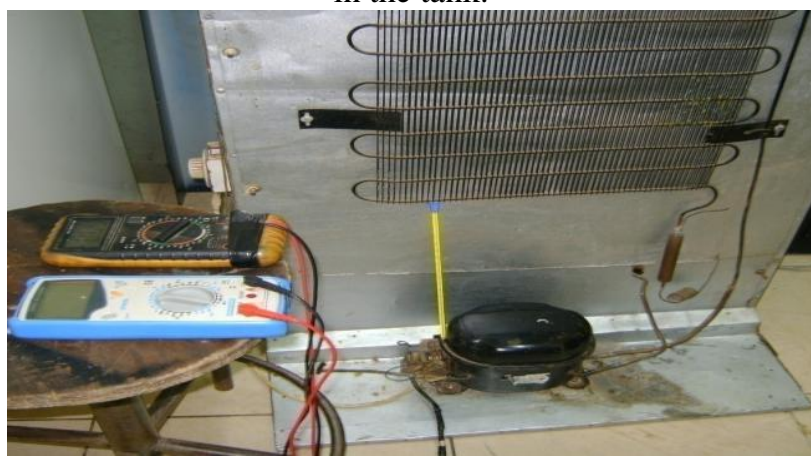

Figure 5 (b): set up for taking the temperature of the normal refrigerators' compressor in operation

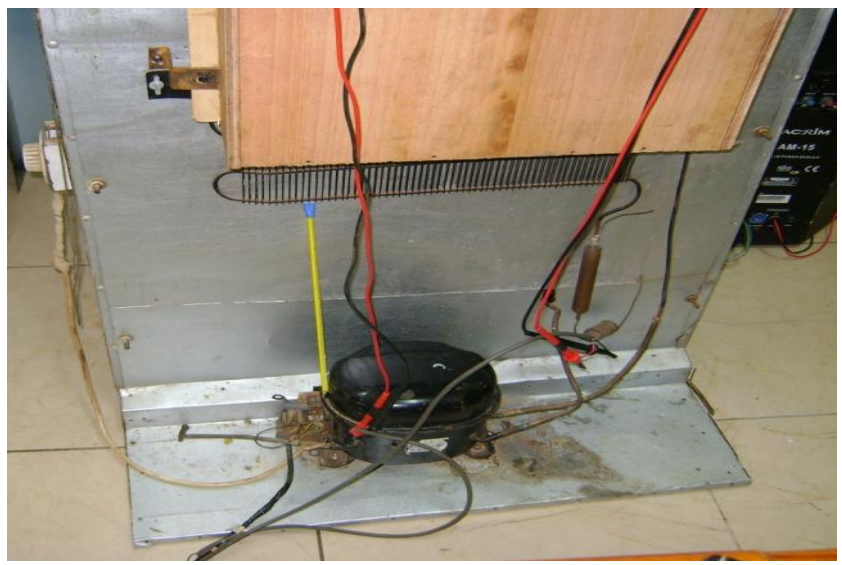

Figure 5 (C): Set up for taking the temperature of the dual purposed refrigerators' compressor in operation 


\section{International Journal of Science and Research (IJSR) \\ ISSN (Online): 2319-7064}

Index Copernicus Value (2015): 78.96 | Impact Factor (2015): 6.391

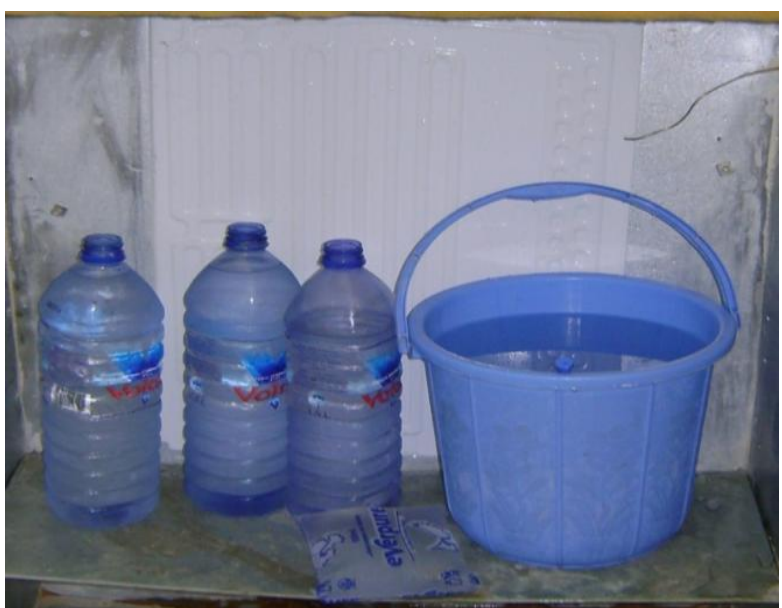

Figure 5 (d): set up for taking the temperature of the water to be cooled in both the normal and the dual purposed refrigerators

\section{Results}

The energy consumption by the compressor, the temperatures: of the water to be heated, the water inside the refrigerator and the compressor during six hours were measured and recorded. The test was carried out at $26^{\circ} \mathrm{C}$ ambient temperature. The data collected for the combined unit and the refrigerator is shown in Tables I and II respectively. The data was used to plot graphs in Excel, which are shown in Figures 6, 7, 8 and 10. The data was also input in SPSS using Paired sample t-test to bring out the output data to aid in the analysis of the experiment. The simplified form of the SPSS output data is found in tables 1,2 and 3. The experiment was conducted for the dual unit and the single refrigerator in order to evaluate the performance of the domestic refrigerator when modified. There were three important data taken: the temperatures of the water placed in the refrigerated space, the temperature of the water inside the tank to be heated and the compressor temperature. The data were analysed according to the theory of refrigeration system. Since the objective of the work was to investigate the effectiveness and power consumption of the two units, therefore it was also closely related to the COP and the compressor power.

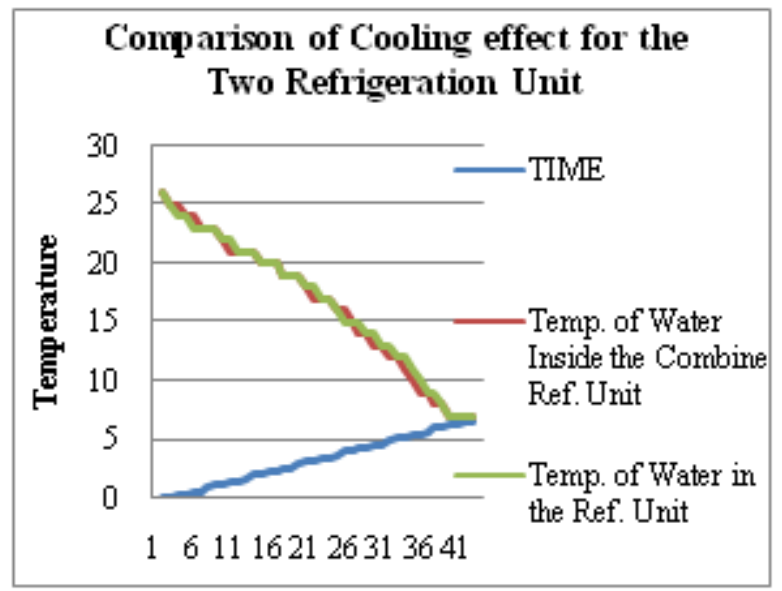

Figure 6: Comparison of the Cooling Effect for the two Refrigerator Unit with Time

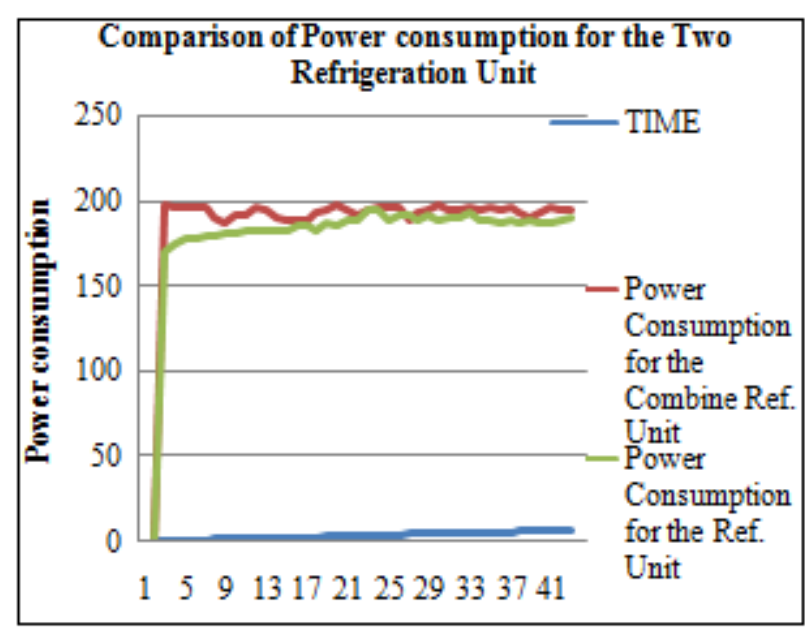

Figure 7: Comparison of the Power Consumption for the two Refrigerator Unit with Time

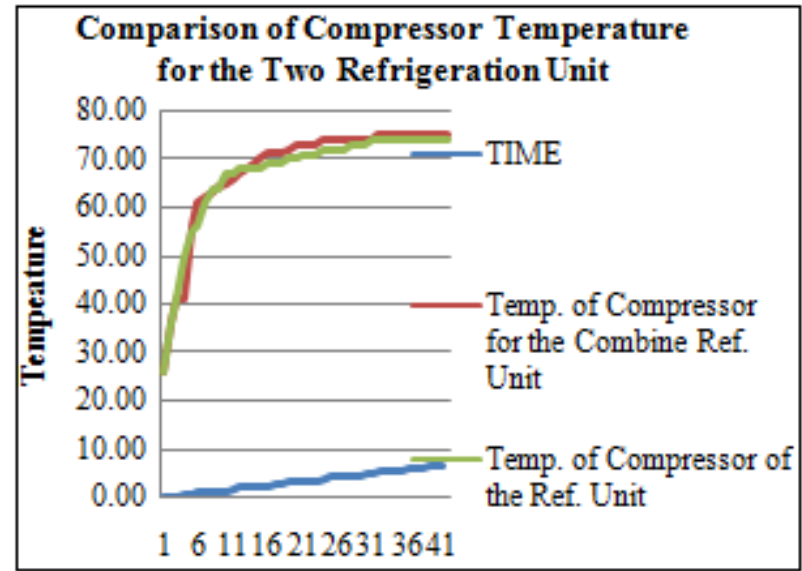

Figure 8: Comparison of the Temperature of the Compressor for the two Refrigerator Unit with Time

Table 1: Summary Statistics of the Effectiveness of the two machines, 1 and 2 (in ${ }^{\circ} \mathrm{C}$ )

\begin{tabular}{|c|c|c|c|c|c|c|c|c|}
\hline M/c & Mean & N & $\begin{array}{c}\text { Std } \\
\text { Dev }\end{array}$ & $\begin{array}{c}\text { Std Error } \\
\text { Means }\end{array}$ & T & Df & r-value & $\begin{array}{c}\text { Sig(2 } \\
\text { tailed) }\end{array}$ \\
\hline M/c 1 & 16.64 & 42 & 5.69 & 0.878 & 1.8 & 41 & 0.996 & 0.83 \\
\hline M/c 2 & 16.50 & 42 & 5.87 & 0.906 & & & & \\
\hline
\end{tabular}

$* \mathrm{M} / \mathrm{c}$ - machine

*Machine 1- Refrigerator without tank; Machine 2-

Refrigerator with tank

Table 2: Summary Statistics of the Power consumption of the two machines, 1 and 2 (in watts)

\begin{tabular}{|l|c|c|c|c|c|c|c|c|}
\hline M/c & Mean & N & $\begin{array}{c}\text { Std } \\
\text { Dev }\end{array}$ & $\begin{array}{c}\text { Std Error } \\
\text { Means }\end{array}$ & T & Df & r-value & $\begin{array}{c}\text { Sig } \\
\text { (2tailed) }\end{array}$ \\
\hline M/c 1 & 189.8 & 42 & 30.13 & 4.648 & 7.9 & 41 & 0.979 & 0 \\
\hline M/c 2 & 182.2 & 42 & 29.28 & 4.518 & & & & \\
\hline
\end{tabular}

$* \mathrm{M} / \mathrm{c}$ - machine

*Machine 1- Refrigerator without tank; Machine 2-

Refrigerator with tank

Table 3: Assessment of the Temperature of the Compressors of the two Machines, 1 and $2\left(\mathrm{in}^{\circ} \mathrm{C}\right.$ )

\begin{tabular}{|c|c|c|c|c|c|c|c|c|}
\hline M/c & Mean & N & $\begin{array}{c}\text { Std } \\
\text { Dev }\end{array}$ & $\begin{array}{c}\text { Std Error } \\
\text { Means }\end{array}$ & T & Df & r-value & $\begin{array}{c}\text { Sig } \\
\text { (2tailed) }\end{array}$ \\
\hline M/c 1 & 67.83 & 42 & 11.59 & 1.788 & 2.8 & 41 & 0.987 & 0.009 \\
\hline M/c 2 & 67.00 & 42 & 10.83 & 1.67 & & & & \\
\hline
\end{tabular}




\section{International Journal of Science and Research (IJSR) \\ ISSN (Online): 2319-7064}

Index Copernicus Value (2015): 78.96 | Impact Factor (2015): 6.391

*M/c - machine

*Machine 1- Refrigerator without tank; Machine 2-

Refrigerator with tank

The experiment was tested at a significance level of 5\% to determine if there is any evidence of the two machines producing different results.

\section{Discussion}

\subsection{Refrigeration effect}

Refrigeration effect is determined using a thermometer to measure the temperature of the water in the refrigerated space. Figure 6 shows graph of the refrigeration effect of the two units versus time for all data. The graph shows a general trend at the first 5 to 10 minutes operation. In the period of time the refrigeration effect for the dualunit was significantly higher than that of the refrigerator and then decreases towards almost constant value with the refrigerator at $7^{\circ} \mathrm{C}$.

This was caused by the load placed against the condenser; preventing it from having a sound heat transfer with the ambient; thereby delaying the condensation process which in turn affected the evaporation process and delay refrigerating effect for some minutes. The refrigeration effect depends partly on the mass flow rate and partly on the enthalpy difference which depends on the temperature of the refrigerated space.

Hence, at certain temperature greater mass flow rate, is required to absorb more heat from the refrigerator space for effective cooling; therefore the dual unit's delayed in cooling was the fact that the condenser was not able to dissipate all the heat to the ambient and therefore the compressor was loaded.

\subsection{Compressor Work}

Figure 8 shows graph of compressor work for 21600 seconds of test run. The graph shows that although the temperature of the combined unit started at a higher temperature value than that of the refrigerator, it shows decrement in it trend until at time 40 minutes of test run the value of compressor work was almost the same with the refrigerator. This situation also is the same trend with graph of the Power consumption; Figure 7. Author can say that the compressor of the dual unit recorded higher values of temperature and power initially due to the additional load of the condenser compelling it to work extra to achieve compression.

The temperatures evolve to be stabilized to $52{ }^{\circ} \mathrm{C}$ for the water in the tank and $7{ }^{\circ} \mathrm{C}$ for the water inside the refrigerated space respectively.

\subsection{Coefficient of Performance}

Coefficient of performance (COP) of the combined unit and the refrigerator were calculated using equation 6 and 4 respectively. Performances of the units were investigated with indicator of COP of 6.36 for the combined unit and a COP of 2.64 for the refrigerator.
4.4 Analysis of temperature variation in water tank with constant load Study is conducted considering an aluminum tank filled with 12 litres of water kept inside the tank and temperatures were noted after specific interval of time. From the analysis, the following were the observations: Mass of water in the tank, $m=12 \mathrm{~kg}$, Specific heat of water, $\mathrm{Cp}=$ $4.184 \mathrm{~kJ} / \mathrm{kgK}$. Initial temperature of water $=26^{\circ} \mathrm{C}$. Final temperature of water in water tank $=52^{\circ} \mathrm{C}$. Final temperature of water in the refrigerator $=7^{0} \mathrm{C}$. Time required for reading, $\Delta \mathrm{t}=21600 \mathrm{~s}$. Heat removal rate by the condenser, Qc:

$Q c=m \times C p \times(\Delta \mathrm{T} / \Delta \mathrm{t})$

$\mathrm{Q}=0.0604 \mathrm{~kJ} / \mathrm{s}$. Heat recovery achieved, $\mathrm{Q}_{\mathrm{con}}=$ Heat Absorbed by Water $=60.4 \mathrm{~W}$.

Refrigerator cooling capacity $=85 \mathrm{kcal} / \mathrm{hr}$. $=$ $85 \times 4.187 \times 1000 / 3600=98.859 \mathrm{~W}$. Power required for running the compressor $=$ Work done on refrigerant $=1 / 4$ $\mathrm{HP}=1 / 4 \times 746=186.5 \mathrm{~W}$.

Heat removal rate by the evaporator, Qev

$Q e v=m \times C p \times(\Delta \mathrm{T} / \Delta \mathrm{t})$

$\mathrm{Q}_{\mathrm{ev}}=0.044 \mathrm{~kJ} / \mathrm{s}$. Heat absorbed by water in the refrigerator $=44 \mathrm{~W}$.

$\mathrm{COP}$ of the dual refrigerator, $\mathrm{COP}_{\text {dual }}$

$\mathrm{COP}_{\text {dual }}=(\mathrm{Qev}+\mathrm{Qc}) /$ Wcomp.

Work of compressor, $\mathrm{W}_{\text {comp }}$

$\mathrm{W}_{\text {comp }}=(\mathrm{Qc}-\mathrm{Qev})$

$\mathrm{W}_{\text {comp }}=16.4 \mathrm{~W}$.

$\mathrm{COP}$ of the refrigerator, $\mathrm{COP}_{\text {ref }}$

$\mathrm{COP}_{\mathrm{ref}}=(\mathrm{Qev} / \mathrm{Wcomp})$

$\mathrm{COP}_{\text {ref }}=2.68$

$\mathrm{COP}$ of the heating system, $\mathrm{COP}_{\text {heating }}$

$\mathrm{COP}_{\text {heating }}=(Q c / \mathrm{Wcomp})$

$\mathrm{COP}_{\text {heating }}=3.68$.

$\mathrm{COP}$ of the dual refrigerator, $=6.36$

\subsection{Output from SPSS}

4.5.1Table 1 shows the summary statistics of the effectiveness produced from machines 1 and 2.The mean effectiveness produced from machine 1 is slightly higher (16.64) than that produced from machine 2 (16.50). Machine 1 recorded a slightly higher consistency(Std. Dev $=5.69)$ in the effectiveness compared to machine 2 (Std.Dev. =5.87). The association between the effectiveness of the two units was very strong $(r=0.997)$ and the significance level (Sig two tailed $=0.86$ ) concludes that there is no significant difference between the effectiveness of the two units.

4.5.2Table 2 shows a summary statistics of the power consumption by the two units, machine 1 and machine 2 . The mean power consumption by machine 1 is slightly higher (189.79) than that consumed by machine 2 (182.21). Machine 2 recorded a slightly higher consistency (Std. Dev. $=29.27$ ) in the power consumption compared to machine 1 (Std. Dev $=30.125$ ). The association between the values of the power consumed is very strong $(r=0.979)$ indicating that the difference is very minimal. A significance value (Sig-two tailed $=0.001$ ) rejects the null of no difference. But then, since the difference in means is minimal, it can therefore be concluded that the difference are not difference that can effect change. 


\section{International Journal of Science and Research (IJSR) \\ ISSN (Online): 2319-7064}

Index Copernicus Value (2015): 78.96 | Impact Factor (2015): 6.391

4.5.3Table 3 shows a summary statistics of the compressor work by the two units, machine 1 and machine 2 . The mean work of the compressor by machine 1 is slightly higher (67.89) than that performed by machine 2 (67.00). Machine 2 recorded a slightly higher consistency $($ Std. Dev. $=10.825)$ in the work performed compared to machine 1 (Std. Dev $=11.536$ ). The association between the values of the power consumed is very strong $(\mathrm{r}=0.987)$ indicating that the difference is very minimal. A significance value (Sig-two tailed $=0.009$ ) rejects the null of no difference. But then, since the difference in means is minimal, it can therefore be concluded that the difference are not difference that can effect change.

\section{Conclusion}

The household refrigerator can also be used as a water heater by coupling a water tank to the conventional air-cooled condenser by the use of brackets and screws which can recover the heat from the condenser and utilized for water heating purpose without change in the effectiveness and power consumption. The fabricated system can result in energy saving due to the non-usage of electrical energy for heating water and cost saving by combining both utilities (refrigeration and heating) in one system. The research has shown that such a system is technically feasible and economically viable.

The maximum temperature achieved in the water tank was $52^{\circ} \mathrm{C}$ and the refrigerating temperature was $7 \mathrm{oC}$.

Actual overall COP of the systems when run with water tank attached is more than the system run with air cooled condenser. Recovery of heat from the condenser reduces the heat load to surroundingand it makessurrounding comfortable.

\section{References}

[1] S. C. Kaushik, M. Singh presents an investigation of the feasibility of HR from the condenser of VCR system through a Canopus heat exchanger (CHE)between the compressor and condenser components (2005)

[2] Sanmati Mirji: a multipurpose warming apparatus utilizing the waste heat of domestic refrigerator (2006)

[3] Mukuna, J.G., Kilfoil, M Technical Feasibility of Combined Refrigerator/Heat Exchanger and Geyser System (2001)

[4] O'Brien. M.J, BansalP.K. a prototyperefrigeration-cumhot water heating system for domestic use. (1998)

[5] Patil Y.A., Dange H. M., Recovered waste heat from condenser unit of household refrigerator to improve the performance of the system by using thermo syphon (2013)

[6] Romdhane Ben Slama Water-heater coupled with the refrigerator to develop the heat of the condenser (2009)

\section{Author Profile}

Esther Benedicta Kyere had her Master of Technology (MTech) degree in 2012 from University of Education Ghana and BSc degree in Mechanical Engineering from Kwame Nkrumah University of
Science and Technology, Ghana in 2009. She attained a Higher National Diploma (HND) in Refrigeration and Air-conditioning Engineering from Takoradi Technical University in 2001. She is currently a lecturer for Refrigeration and Air-conditioning Engineering at the Takoradi Technical University in Ghana.

Professor Martin Amoah is a lecturer at the department of Design and Technology Education at the University of Education, Winneba in Ghana. He has a PhD in Forest and Wood Utilisation.

Volume 6 Issue 7, July 2017 www.ijsr.net 